REVISTA CIENTÍFICA RURAL

ISSN: 1413-8263 2525-6912
Revista Técnico-Científica

\title{
EFEITOS DO FENÔMENO GERMINAÇÃO PRÉ-COLHEITA NA PRODUÇÃO DE TRITICALE (x Triticosecale Wittmack)
}

${ }^{1}$ Carlos Henrique dos Santos Fernandes, ${ }^{1}$ Débora Perdigão Tejo, ${ }^{2} \mathrm{Klever}$ Márcio Antunes Arruda

1Universidade Norte do Paraná - Graduação em Agronomia, (carloshenrique_fernandes_@hotmail.com; deboratejo@hotmail.com). ${ }^{2}$ Eng. Agr. Pesquisador, Instituto Agronômico do Paraná, Londrina, Pr, (klever@iapar.br).

RESUMO: O fenômeno da germinação na espiga tem sido observado ao longo de muitos anos, e em várias áreas produtoras de triticale em todo o mundo, sendo considerado um problema agronômico, pois, representa um fator limitante de qualidade tecnológica para a indústria e de qualidade fisiológica para a produção de sementes. 0 objetivo deste estudo foi conceituar a germinação pré-colheita, expondo os prejuízos para o triticale em relação à qualidade tecnológica para a indústria de transformação e para qualidade fisiológica de sementes. A metodologia utilizada foi pesquisa em base de dados de publicações cientificas e consultas em livros. $O$ processo de germinação pré-colheita é similar a germinação no solo, porém ocorre na espiga sendo ocasionado por determinadas condições climáticas favoráveis. Em campos de produção de sementes os prejuízos são verificados por meio da redução de viabilidade, podendo comprometer a comercialização dos lotes. Em relação à qualidade de grãos destinados a indústria para a panificação, os prejuízos são constatados na farinha, sendo resultado de alterações provocadas em ações enzimaticas. Concluiu-se que a ocorrência de germinação pré-colheita acarreta prejuízos na qualidade fisiológica das sementes e qualidade tecnológica para as indústrias de grãos de triticale um dos principais produtos obtidos dos grãos de triticale.

Palavras-chave: qualidade de grãos, enzimas, panificação, Pre-harvest Sprouting.

\section{EFFECTS OF PRE-HARVEST GERMINATION PHENOMENON IN TRITICALE PRODUCTION (x TriticosecaleWittmack)}

ABSTRACT: The spike germination phenomenon has been observed for many years, and in several triticale producing areas around the world, being considered an agronomic problem, as it represents a limiting factor of technological quality for industry and physiological quality for seed production. The objective of this study was to conceptualize pre-harvest germination, exposing the damage to triticale in relation to technological quality for the processing industry and for physiological seed quality. The methodology used was database research of scientific publications and consultations in books. The pre-harvest germination process is similar to soil 
germination, but occurs on the ear and is caused by certain favorable climatic conditions. In seed production fields the losses are verified through the reduction of viability, which may compromise the commercialization of the lots. Regarding the quality of grain destined for the bakery industry, the damage is found in the flour, resulting from changes caused by enzymatic actions. It was concluded that the occurrence of pre-harvest germination causes damage to the physiological quality of seeds and technological quality for the triticale grain industries, one of the main products obtained from triticale grains.

Keywords: quality of grains, enzymes, baking, Pre-harvest Sprouting.

\section{INTRODUÇÃO}

O triticale (x Triticosecale Wittmack) é uma gramínea de estação fria desenvolvida através do cruzamento artificial entre as espécies de trigo (Triticum sp.) e centeio (Secale cereale L.), tal cruzamento foi promovido com propósito de reunir características favoráveis destas duas espécies. Entre estas características destacam-se, alto potencial produtivo e excelente qualidade para panificação da cultura do trigo; já do centeio almeja-se a possibilidade de cultivo em locais com solos arenosos, e resistência a algumas doenças fúngicas. Apesar do triticale não agrupar todas as características desejáveis de seus genitores, merece destaque sua alta produção de biomassa e maior rendimento de grãos em condições de déficit hídrico e/ou de baixa fertilidade do solo. O intuito de seu desenvolvimento foi combinar características de alta produtividade e valor energético do trigo, com a qualidade protéica e a rusticidade do centeio (RANDHAWA et al., 2015).

Os grãos produzidos pelo triticale são destinados a alimentação humana, com destaque para alimentação animal em forma de ração, podendo ser uma alternativa eficiente comparado aos grãos de milho. Para alimentação humana seu desempenho ainda é pouco significativo, porém é possível destiná-lo a panificação por meio a produção de farinha. Por se tratar de uma cultura que traz muitos benefícios, seu produto vem sendo valorizado, passando a ser desbravado pelos produtores agrícolas como uma alternativa para safra de inverno (NASCIMENTO JUNIOR et al., 2004).

Apesar de apresentar maior competitividade em relação a outros cereais de inverno, o triticale ainda possui deficiências em algumas características agronômicas, dentre elas à germinação na espiga ou germinação em pré-colheita. A 
germinação em pré-colheita em inglês Pre-harvest Sprouting (PHS), é definida como a germinação prematura dos grãos na espiga antes da colheita, sendo um fenômeno ocasionado por períodos de chuvas excessivas e elevada umidade relativa do ar antes da colheita, no período em que o grão já está maduro; a ocorrência de tal evento resulta em prejuízos a qualidade tecnológica para grãos e fisiológica para sementes (JANDREY, 2013).

Visto isto, o objetivo deste trabalho foi conceituar o fenômeno de germinação em pré-colheita, evidenciando os problemas ocasionados, enfatizando os prejuízos em relação a qualidade tecnológica para a indústria de transformação e de qualidade fisiológica para a produção de sementes.

\section{MATERIAL E MÉTODOS}

O presente trabalho trata-se de uma revisão de literatura, elaborado em cima de consultas em livros, dissertações, artigos publicados em revistas com teor científico e boletins técnicos emitidos por Instituições renomadas como FAOSTAT, Conab, Embrapa, entre outros. Os materiais foram buscados nas bases de dados Google Acadêmico e Scielo, sendo utilizadas as palavras chaves: $\mathrm{x}$ Triticosecale Wittmack; germinação pré-colheita; dormência.

\section{GERMINAÇÃO PRÉ-COLHEITA}

O fenômeno de germinação pré-colheita ou precoce é semelhante ao processo natural de germinação de sementes no solo ou em substratos, no entanto a germinação pré-colheita caracteriza-se por ocorrer nos tecidos vegetais da própria planta, mais especificamente na espiga, devido à ocorrência de chuvas próxima â época de colheita resultando no fenômeno germinação pré-colheita. (JANDREY, 2013). O problema se manifesta em regiões onde ocorrem precipitações por um período relativamente prolongado de três a quatro dias, dependendo da intensidade próxima da maturação fisiológica (NÖRNBERG, 2012).

A germinação precoce ocorre quando a semente entra em contato com água e acontece a embebição, disparando uma sequência de processos fisiológicos, entre os quais, a liberação de hormônios e de enzimas hidrolíticas. Considerando um processo simplificado, a atividade hormonal do ácido giberélico (GA) na semente 
embebida induzirá a síntese de amilases; as reservas de carboidratos serão hidrolisadas e translocadas para o embrião, onde serão utilizadas no seu desenvolvimento. Segundo Kuo et al. (1996), a função da camada de aleurona dos cereais, durante a germinação, é a secreção de hidrolases, principalmente a alfaamilase, no endosperma. Existem vias de tradução de sinais múltiplas em células da aleurona dos cereais que Ihes permitem modular a produção de hidrolases em resposta aos estímulos hormonais e ambientais. É bem estabelecido que o ácido abscísico (ABA) promove a dormência e reprimi a germinação das sementes, pela redução da produção de amilases, enquanto, que $0 \mathrm{GA}$, antagonicamente, desencadeia a germinação das sementes, pela promoção da produção de hidrolases (KUCERA et al., 2005). Ou seja, os hormônios possuem uma forte influência sobre a regulação da dormência e da germinação das sementes. Por sua vez, os genes que codificam as proteínas que modulam o metabolismo destas moléculas sinalizadoras (especialmente os envolvidos na biossíntese e desativação de GA e ABA) são os principais reguladores genéticos destes eventos (SEO et al., 2009).

O problema da germinação na espiga tem sido observado ao longo de muitos anos e em várias áreas produtoras de triticale e trigo em todo o mundo, representando um fator limitante de qualidade tecnológica para a indústria de transformação e de qualidade fisiológica para a produção de sementes. No entanto, a germinação na espiga ocorre principalmente nas regiões de cultivo mais quentes, onde temperaturas elevadas ocasionam a superação da dormência dos grãos e facilitam a germinação. É bem estabelecido que a temperatura afeta a velocidade de absorção de água e a velocidade dos processos metabólicos da semente. Com isso, para que a germinação na espiga se manifeste duas condições são requeridas: superação da dormência durante o enchimento de grãos, e chuvas após a maturação fisiológica da semente (MOŚ e WÓJTOWICZ, 2004; CHAPMAN, 2011).

\section{PREJUÍZOS EM FUNÇÃo DA GERMINAÇÃo PRÉ COLHEITA NA CULTURA DO TRITICALE}

O triticale em relação aos demais cereais de inverno cultivados é uma cultura relativamente nova e extremamente suscetível a ocorrência de germinação précolheita; o nível de alfa-amilase desta cultura é elevado. A elevação das atividades 
enzimáticas leva a uma redução significativa na massa seca dos grãos; variações na produção de aminoácidos; aumenta os teores de sacaroses, lipídios, nutrientes e minerais (MORAD, RUBENTHALER, 1983). Sendo assim a ocorrência de chuvas na época da colheita, afeta a qualidade do grão para fins indústrias e para produção de sementes (TACHIBANA, 2010).

A taxa de prejuízos atribuída à germinação na espiga está relacionada a vários fatores, abrangendo temperatura, quantidade e intensidade de chuvas, nível de secagem do grão, estrutura da cariopse, morfologia da espiga, presença ou ausência de genes de resistência à germinação e estádio de maturação da cultura na lavoura (OKUYAMA et al., 2017).

Em anos agrícolas em que as chuvas são elevadas as espigas tornam-se mais suscetíveis a germinação pré-colheita, sendo esta capaz de ocasionar prejuízos aos parâmetros de rendimento de grãos e o peso do hectolitro $(\mathrm{PH})$, podendo atingir valores abaixo do valor de $\mathrm{PH}$ mínimo normalmente verificado nas cultivares de triticale recomendadas para cultivo no Brasil; $\mathrm{PH}$ frequentemente constatado em condições ideais está na faixa entre 62 e $79 \mathrm{~kg} / \mathrm{hl}$. Valores considerados baixos para o parâmetro de $\mathrm{PH}$ correspondem a uma deficiência no preenchimento intrínseco dos grãos, estando relacionado a grãos de baixo valor energético, no entanto com altos índices de proteína bruta (TACHIBANA, 2010).

As consequências da germinação na espiga em triticale envolvem perdas quantitativas na colheita; redução na viabilidade da semente; redução na qualidade do grão para fins industriais, resultante da síntese e da ação de enzimas hidrolíticas, como alfa-amilase no endosperma da semente (BRASIL, 2001; DERERA, 1989). É provável que as perdas anuais ocasionadas pela germinação na espiga de triticale e trigo se aproximem de US $\$ 1$ bilhão em todo o mundo (Black et al., 2006).

Além das perdas no rendimento do produto final colhido, a germinação na espiga também ocasiona sérios problemas a fatores da qualidade da farinha oriunda destes grãos. Os resultados no processo de panificação utilizando grãos germinados podem ser observados em pães de dimensões abaixo do esperado, com interior compactado e casca muito escura; em macarrão com coloração escurecida e bolos desestruturados (LORENZ; D'APPOLONIA, 1980). 
Ainda não há muitos relatos em relação aos prejuízos ocasionados pela germinação na espiga na qualidade fisiológica de sementes, no entanto sabe-se que o processo pré-germinativo provoca alterações enzimáticas e decomposição de tecidos de reserva, reduzindo assim os níveis de viabilidade e vigor dos lotes oriundos de áreas com a incidência de tal fenômeno (BARNARD; PURCHASE, 1999).

Mensurar os prejuízos mundiais na cultura do triticale ocasionados pelo processo de germinação pré-colheita é algo complexo, no entanto para determinadas culturas existem dados estimando que em determinadas condições os prejuízos por este fenômeno de germinação pré-colheita, conhecido mundialmente, atingem de $30 \%$ a $75 \%$ da produção (JIANG, 1999).

\section{FATORES INTRÍNSECOS AO GRÃO DE TRITICALE}

O embrião de uma semente de triticale que esteja com metade de sua maturação finalizada é capaz de germinar, entretanto até que se atinja $70 \%$ de maturação das sementes as células da aleurona ainda não estão maduras, sendo assim processos germinativos e a capacidade da aleurona em sintetizar a enzima alfa-amilase são retraídos até que se atinja o desenvolvimento da semente e com isso subsequentemente a perda de umidade (HILHORST, 1995).

As enzimas hidrolíticas podem ser produzidas em qualquer região de uma semente após iniciar o processo germinativo, se destacado a camada de aleurona. Mares (1987), por meio de seus estudos comprovou que no embrião, com destaque para a estrutura denominada escutelo, produz alfa-amilase mesmo que em baixa quantidade, este foi o primeiro relato de alfa-amilase identificada em grãos que não iniciaram o processo germinativo; tal produção no escutelo corresponde de 5 a $10 \%$ apenas do total de alfa-amilase sintetizada nas sementes (RANKI; SOPANEN, 1984).

Dentre as enzimas capazes de hidrolisar o amido, a alfa-amilase é considerada a mais importante, por tanto a degradação do amido varia conforme a habilidade da enzima alfa-amilase em desempenhar tal função, outras enzimas 
também contribuem para este processo sendo elas, B-amilase, B-glucanase, enzimas desdobradoras de amido e B-glucosidade (HENSON, IM, 1996).

\section{ALTERNATIVAS PARA O CONTROLE DA GERMINAÇÃO NA ESPIGA}

É quase consenso que poucas são as alternativas para se contornar o problema de germinação pré-colheita em triticale via práticas culturais. Exceto pela escolha de cultivares resistente a germinação na espiga, escalonamento na época de semeadura e da colheita, envolvendo áreas preferenciais para iniciar a colheita, cultivares mais precoce, pelas quais deve se iniciar a colheita. Uma solução definitiva para o problema, embora questionável por diferentes motivos, seria a incorporação de gene Terminator em triticale (TRETHOWAN, 2001), pois ele impediria a germinação independentemente de qualquer circunstância. Há também a alternativa, apontada por Trethowan (2001), de identificação de gene ou genes (Temporal Repressor Gene) que reprimam o processo de germinação pré-colheita em campo.

As características da espiga e das sementes são importantes por diversos aspectos que interagem com os fatores causadores da germinação na espiga. Um exemplo disso é o envolvimento da precipitação pluvial durante as fases de maturação e colheita com a quantidade de umidade presente na espiga, que tem interação com características estruturais da espiga, favorecendo ou dificultando o acúmulo de água (KING, 1993).

Dentre estás também se destacam a manutenção da dormência por meio de barreira física, controle químico e regulação metabólica (KING, 1993). Em contraste as giberelinas, o regulador de crescimento de plantas, ácido abscísico, inibe a germinação em cereais, bloqueando a transcrição do gene indutor de GA e, consequentemente, a produção de enzimas, enquanto, simultaneamente, dispara a produção de proteínas especificas uma das quais é inibidora da alfa-amilase (KUCERA et al., 2005). Embora enzimas como a alfa-amilase tenham sido caracterizada, com o estabelecimento de sua localização anatômico nas sementes em germinação, existem enzimas pouco conhecidas que merecem ser mais estudadas (KRUGER, 1994). 
Em resumo, GA e ABA atuam no processo da germinação, e os papeis desempenhado pelo GA aplicado abrange promover o processo de germinação; disparam uma secreção de enzimas hidrolíticas, controlada pelo embrião; linhas com diferenças em potencial para a produção de alfa-amilase podem, também, diferir na dependência de GA (AMARO, 2009). Já o papel desempenhado pelo ABA aplicado é inibir os processos realizados pelo GA, ou seja, o $A B A$ aplicado bloqueia a ação do GA e dispara a produção de proteínas especificas, incluindo um inibidor de alfa-amilase (AMARO, 2009).

Outro componente envolvido na germinação que merece destaque é o efeito do tamanho da semente e do número de sementes por espiga. Sementes pequenas periféricas germinam mais rapidamente. Assim, a seleção buscando sementes de maior tamanho pode ser importante. Além disso, a seleção de espigas com poucas espiguetas e mais sementes por espiguetas pode também reduzir a proporção de sementes germinadas. O maior problema nessa situação é o possível efeito adverso no rendimento (KING, 1984).

Outra característica, possivelmente relacionada com a resistência à germinação pré-colheita, é a coloração de sementes de trigo e triticale. Esse aspecto foi muito importante na definição de cultivares comercial. Cultivares com sementes brancas são consideradas como suscetível à germinação pré-colheita, e as de coloração vermelha exibem grande variação na resistência ao problema (NÖRNBERG, 2012).

Estudos realizados por Moss (1972) indicou que todos os genótipos de triticale australianos possuíam sementes de coloração branca. Nessa época, não foi identificada tolerância à germinação pré-colheita entre as cultivares testadas de coloração branca, sendo a extensão do dano causada pelo ambiente dependente de temperatura e chuva e do estádio de maturação das plantas em que o dano ocorreu. Por tais motivos, esses autores sugeriram a reabertura das discussões sobre a exclusão de cultivares de coloração vermelha da classificação comercial da Austrália.

Estudos comparando cultivares de coloração branca e vermelha em triticale e trigo indicaram que a cor da semente, dormência, atividade da enzima alfa- 
amilase e o número de queda, foram relacionados com a resistência à germinação pré-colheita (JIANG, 1999).

A importância da morfologia em limitar a embebição do grão na espiga e em restringir a germinação foi demonstrada por Okuyama (2017). Usando um simulador de chuva, esses autores observam que a embebição da espiga, medida após uma hora ou 24 horas, e a germinação na espiga, medida após 30 horas, variaram grandemente entre cultivares, sendo parte dessa variação atribuída à presença de aristas. As linhas não-aristadas absorveram, significativamente, menos água e foram menos propensas à germinação na espiga. Respostas similares foram encontradas em linhas isogênicas para o caráter arista/sem arista. Embora as linhas aristadas sejam mais suscetíveis a danos por chuvas, as aristas, por si só, parecem não ter influência e a remoção destas não faz diferença. Espigas com aristas e espigas com aristas removidas, da mesma cultivar absorveram água na mesma proporção (OKUYAMA, 2017).

Evidências indicam que em espigas pendentes a água escorre mais rapidamente em chuvas torrenciais e rápidas. No entanto, isso não da proteção contra chuva fraca e duradoura (chuva de encharcamento). O mesmo se aplica a glumas extremamente aderentes, como as encontradas em trigos espeltóides. $\mathrm{O}$ oposto é, de fato, manifestado em culturas que apresentam as glumas mais abertas, particularmente o centeio que absorvem água mais rapidamente e, consequentemente, a germinação acontece se a dormência não está presente (DERERA, 1989). As espigas de cultivares aristadas absorvem água mais rapidamente do que as não-aristadas. Também, as cultivares de espigas clavadas aumentam a taxa de absorção de água (KING, 1993).

Vários fatores podem contribuir para uma maior tolerância à germinação na espiga, como a diminuição dos graus de alfa-amilase nas sementes, o aparecimento de inibidores de germinação, diminuição da embebição de água pelas sementes e soluções alteradas para hormônios (FLINTHAM, 2000). Adicionalmente, a escassez de dormência apropriada para as sementes é a razão fundamental para a germinação na espiga, sendo destacada como uma característica dirigida por inúmeros genes (LI et al., 2004). 
No entanto, um dos grandes desafios para a geração de genótipos com reduzida germinação pré colheita continua sendo a presença de efeitos epistáticos e o grande efeito do ambiente (GAVAZZA et al., 2012).

\section{METOdOLOGIAS PARA DIAGNÓSTICO DO PROBLEMA DE GERMINAÇÃO PRÉ-COLHEITA NO TRITICALE}

Em caso de condições meteorológicas desfavoráveis que afetem a lavoura na pré-colheita, é imprescindível que técnicas sejam disponibilizadas para avaliar a extensão dos danos provocados nos grãos colhidos, essa avaliação é de grande importância para a predição de prováveis efeitos no uso industrial do produto. Todos os segmentos da indústria requerem um teste objetivo e confiável para determinar os danos por germinação na espiga, com o intuito de maximizar seus retornos financeiros usando o grão eficientemente (MALAKSHAH, 2016).

Quando o momento da colheita é afetado por chuvas constantes, amostra de grãs apresenta grande variação de danos que podem ser devidamente identificados. Inicialmente, os danos podem ser mínimos, dependendo do uso final a que se destina o grão, embora pequena quantidade de danos possa não ser obvia num teste subjetivo, mas podem ser facilmente detectados num teste químico objetivo (MALAKSHAH, 2016).

Existem vários métodos descritos na literatura para avaliar a resistência à germinação na espiga, onde as metodologias desenvolvidas para a determinação de germinação podem requerer o uso de câmaras de germinação com alta umidade relativa e o emprego de simuladores de chuva (GAVAZZA et al., 2012; HUMPHREYS; NOLL, 2002).

Independentemente dos procedimentos adotados para induzir a germinação e assim possibilitar a diferenciação dos genótipos, a maioria destes métodos utiliza-se da avaliação visual dos grãos e do Número de Queda (Falling Number), que quantifica o grau de alfa-amilase no grão, assim possibilitando correlacionar a germinação com a dormência dos grãos (HUMPHREYS; NOLL, 2002; JOHANSSON, 2002). 


\section{CONCLUSÕES}

A germinação na espiga traz prejuízos a qualidade fisiológica das sementes e qualidade tecnológica para as indústrias de grãos de triticale; por consequência afeta a qualidade da farinha destinada à panificação, um dos principais produtos obtidos dos grãos de triticale. De este modo desenvolver cultivares de triticale tolerante a germinação na espiga é um possibilidade de reduzir a incidência do fenômeno de germinação na espiga na cultura do triticale.

\section{REFERÊNCIAS}

AMARO, A. C. E. Combinations between GA4+ 7+ N-(phenyl methyil)-aminopurin and ethephon in germination of Passifloracincinnata Mast seeds. Revista Brasileira de Sementes, v. 31, n. 1, p. 195-202, 2009.

BARNARD, Annelie, PURCHASE, John Luscombe. The effect os seed treatment and preharvest sprouted seed on the emergence and yield of winter wheat in South Africa. In: INTERNATIONAL SYMPOSIUM ON PRE-HARVEST SPROUNTING IN CEREALS, 8., 1999, Detmold, Germany. Proceedings... Detmold: Association of cereal Research and Federal Centre for Cereal, Potato and Lipid Research, 1999. P. 26-35.

BEWLEY, J. Derek; BLACK, Michael; HALMER, Peter (Ed.). The encyclopedia of seeds: science, technology and uses. Cabi, 2006.

BRASIL. Ministério da Agricultura e da Reforma Agraria. Secretaria Nacional de Defesa Agropecuaria - Departamento Nacional de Produção e Defesa Vegetal Coordenação de Laboratório Vegetal. Regras de análise de sementes. Brasilia, 2001. $545 \mathrm{p}$.

CHAPMAN, B. Economic impact of pre-harvest sprouting, seed dormancy and germination from a famer perspective. Proc 12th Int Symp Pre-harvest sprouting in cereals, Alberta, Canada, p. 11, 2011.

DERERA, Nicholas. Breeding for preharvestsprountingtolerance. In: DERERA, n. f. Preharvest sprounting field in cereals. Boca Raton: CRC Press, 1989. P. 11-128.

FLINTHAM, J.E. Different genetic components control coat-imposed and embryoimposed dormancy in wheat. Seed Science Research, v. 10, p. 43-50, 2000.

GAVAZZA, M.I.A.; BASSOI, M.C.; CARVALHO, T.C.; BESPALHOK FILHO, J.C.; PANOBIANCO, M. Methods for assessment of pre-harvest sprouting in wheat cultivars. Pesquisa Agropecuária Brasileira, v. 47, n. 7, p. 928-933, 2012.

HENSON, Cynthia; IM, Hana. Starch degradation in germinating barley seeds. In: INTERNATIONAL SYMPOSIUM ON PRE-HARVEST SPROUNTING IN CEREALS, 
7., 1996, Osaka. Proceedings... Osaka: Center for Academic Societes, Japan, 1996. P. 341-347.

HILHORST, Henk. A critical update on seed dormancy. 1. Primary dormancy. Seed Science Research, v. 5, p. 61-73, 1995.

HUMPHREYS, Dalton; NOLL, John. Methods for characterization of preharvest sprouting resistance in a wheat breeding program. Euphytica, v. 126, p. 61-65, 2002.

JANDREY, Paulo Evandro. Tolerância a germinação na espiga e produtividade de grãos de genótipos de trigo em duas épocas de semeadura. 2013. $61 \mathrm{f}$. Dissertação (Mestrado em Agronomia) - Universidade Estadual do Oeste do Paraná, Marechal Cândido Rondon, 2013.

JIANG, Guang-Shan. Studies on preharvest sprounting and relative traits in red and White wheat. In: INTERNATIONAL SYMPOSIUM ON PRE-HARVEST SPROUTING IN CEREALS, 8., 1999, Detmold, Germany. Proceedings...detmold: Association of Cereal Research and Federal Cereal, Potato and Lipid Research, 1999. P. 310-315.

JOHANSSON, E. Effect of two wheat genotypes and Swedish environment on falling number, amylase activities, and protein concentration and composition. Euphytica, v. 126, n. 1, p. 143-149, 2002.

KING, Rod, et al. Absciic-acid and gibberellin action in developing kernels of triticale (cv. 61919). Planta, Berlin, v. 146, p. 249-255, 1984.

KING, Rod. Manipulation of grain dormancy in wheat. Journal of Experimental Botany, Oxford, v. 44. P. 1059-1066, 1993.

KRUGER, James. Enzymes of sprouted wheat and their possible technological significance. In: BUSHUK, W.; RASPER, V. F. (Ed.). Wheat: production, properties, quality. London: Chapman \& Hall, 1994. 239 p. Chap. 10, p. 143-153.

KUCERA, B.; COHN, M.A.; LEUBNER-METZGER, G. Plant hormone interactions during seed dormancy release and germination. Seed Science Research, v.15, p. 281-307, 2005.

KUO, Anling, et al. Okadaic Acid, a Protein Phosphatase Inhibitor, Blocks Calcium Changes, Gene Expression, and Cell Death Induced by Gibberellin. In: Wheat Aleurone Cells. The Plant Cell, v. 8, p. 259-269, 1996.

LI, C.; NI, P.; FRANCKI, M.; HUNTER, A.; ZHANG, Y.; SCHIBECI, D.; LI, H.; TARR, A.; WANG, J.; CAKIR, M.; YU, J.; BELLGARD, M.; LANCE, R.; APPELS, R. Genes controlling seed dormancy and pre-harvest sprouting in a rice-wheat-barley comparison. Functional e Integrative Genomics, v. 4, p. 84-93, 2004.

LORENZ, Klaus; D'APPOLONIA, Bert. Cereal sprouts: composition, nutritive value, food applications. Critical Reviews in Food Science and Nutrition, v. 13, n. 4, p. 353-385, 1980. 
MALAKSHAH, Ahmad Ahmadpour. Real Time PCR Analysis of a-amylase Gene Expression in Spring Wheat during Pre-Harvest Sprouting. Advances in Bioresearch, v. 7, n. 3, 2016.

MORAD, Matias, RUBENTHALER, Gariel. Germination of soft white wheat and its effect in flour fractions, breadbaking, and crumb firmness. Cereal Chemistry, v. 60, n. 6, p. 413-417, 1983.

MOŚ, M.; WÓJTOWICZ, T. The effect of seed sprouting damage on field emergence and yield of spring triticale. Journal of Central European Agriculture, v. 5, p. 251258, 2004.

MOSS, $\mathrm{H}$. Effect of pre-harvest rain on germination in the ear and a-amylase activity of australian wheat. Australian Journal of Agricultural Research, Melbourne, v. 23, n. 5, p. 769-777, 1972.

NASCIMENTO JUNIOR, A. et al. Triticale improvement and production. $1^{\text {st }}$ ed, FAO, Roma, p. 93-98, 2004.

NÖRNBERG, Rafael. Characterization and prediction of parents seeking tolerance to pre-harvest sprouting in wheat (Triticum aestivum L.). 2012. 133 f. Dissertação (Mestrado em Agronomia) - Universidade Federal de Pelotas, Pelotas, 2012.

OKUYAMA, Lauro Akio, et al. Preharvestsprouting assessment in wheat genotypes influenced by temperature and degreedays. Experimental Agriculture, p. 1-8, 2017.

RANDHAWA, Harpinder Sandhu; BONA, Laura.; GRAF Robert. Triticale breedingProgress and prospect. In Eudes F. (ed) Triticale. Springer, New York, p. 69-81, 2015 .

RANKI, Harri, SOPANEN, Tuomas. Secretion of alfha-amylase by the aleurone layer and the scutellum of germinating barley grain. Plant physiology, Rockville, v. 75, p. 710-715, 1984.

SEO, M.; NAMBARA, E.; CHOI, G.; YAMAGUCH, S. Interaction of light and hormone signals in germinating seeds. Plant Molecular Biology Reporter, v. 69, p. 463-472, 2009.

TACHIBANA, Leonardo et al. Substituição do milho pelo triticale na alimentação de tilápias-do-nilo. Revista Brasileira de Zootecnia, p. 241-246, 2010.

TRETHOWAN, Richard. Avances em elmejoramiento de trigos tolerantes a brotación de la espiga. In: SEMINARIO INTERNACIONAL: ESTRATEGYAAS Y METODOLODÍAS UTILIZADAS EM EL MEJORAMIENTO DE TRIGO, Uruguai., p. 25, 2001. 